\title{
JUSTICIA ALTERNATIVA EN EL ESTADO DE CHIHUAHUA
}

\author{
WENDOLYNE NAVA
}

\section{RESUMEN}

In México, la justicia alternativa ha pasado por varias etapas. Actualmente se encuentran reconocidos a nivel cons-

Litucional, sin embargo, en el estado de Chihuahua su implementación no ha sido fácil. El presente trabajo expone el recorrido histórico de estos sistemas en sede judicial, así como las expectativas hacia el futuro.

Palabras claves: Justicia Alternativa, solución de conflictos, mediación, ADR en sede Judicial, Estado de Chihuahua.

\section{Nota introductoria}

Tradicionalmente en un estado de derecho, el monopolio de la jurisdicción recae en el poder judicial. Desde esta perspectiva, pareciera inadmisible pensar que los ciudadanos privadamente, sea en forma individual o sea a través de sus organizaciones comunales o familiares, pudieran resolver sus problemas, o que el Estado promoviera métodos alternativos para gestionar los conflictos entre los gobernados. 
Es de destacar que esta concepción en la actualidad está empezando a cambiar, los gobiernos en diversas partes del mundo ${ }^{1} \mathrm{y}$, particularmente en México, están apostando por los mecanismos extrajudiciales de resolución de litigios, también conocidos por sus siglas en inglés: ADR, ${ }^{2}$ como una opción idónea para solucionar cierto tipo de disputas, principalmente por las características que poseen estos sistemas alternos tales como flexibilidad, rapidez, bajo costo y sobre todo por el hecho de que proporcionan a las partes una opción eficaz y eficiente, en virtud de que el procedimiento puede ser adaptado a sus circunstancias particulares sin las formalidades estrictas de un proceso tradicional ante tribunales. Sin embargo, a pesar de los evidentes beneficios de los ADR, estos todavía no logran consolidarse de la forma esperada.

Así, el objetivo de este trabajo es mostrar la evolución de los mecanismos extrajudiciales de resolución de conflictos en sede judicial, particularmente en el estado de Chihuahua, así como también poner de manifiesto las diversas aristas que los ADR enfrentan en la actualidad en su camino por convertirse en un verdadero acceso a la justicia para la ciudadanía en general. A fin de lograr dicho propósito, el desarrollo de este trabajo contempla su división en tres apartados. El primero de ellos tratará brevemente los antecedentes históricos de los mecanismos extrajudiciales de resolución de conflictos en términos generales. La segunda parte se enfocará en los ADR en el estado de Chihuahua, haciendo énfasis, situación en que se encuentran actualmente en dicha entidad federativa en particular y en el país en general, para finalizar haciendo una serie de reflexiones en cuanto a las expectativas de estos mecanismos extrajudiciales de resolución de conflictos hacia el futuro.

1 En Estados Unidos, Canadá, Latinoamérica, la Unión Europea, Asia e incluso algunos países en África, los mecanismos extrajudiciales de resolución de conflictos son ampliamente utilizados.

2 ADR: Alternative Dispute Resolution. 


\section{ANTECEDENTES DE LOS ADR}

Las modalidades convencionales de resolución de los litigios no son novedosas; desde tiempos inmemorables las personas han utilizado la mediación, la conciliación y el arbitraje como método para resolver sus diferencias (Barret, 2004, pp. 1-2), las sociedades han contado tradicionalmente con sistemas propios para la resolución de conflictos sin acudir al poder central.

En la antigua Grecia se hacía uso de estos procesos al surgir algún problema de propiedad o económico entre dos ciudades pequeñas, estas apelaban a una población más grande o poderosa para que resolviera sus disputas a través del arbitraje. En muchas ocasiones, las decisiones que tomaban los árbitros eran inscritas en las paredes y pilares del famoso Templo de Delfi (Barret, 2004, pp. 3-4).

En Roma, el proceso formulario, surgido en el periodo clásico de su jurisprudencia, constituye un ejemplo de un arbitraje oral y expedito, en el cual se permitía a las partes no solo elegir al juez, sino también definir el objeto del litigio. ${ }^{3}$ Asimismo, las Leyes de las XII Tablas otorgaban fuerza obligatoria a lo que las partes convinieran en juicio (Mancur, 2002, p. 15). Por su parte, Cicerón aconsejaba la conciliación fundado en el aborrecimiento que debía tenerse a los pleitos, diciendo que "ella era un acto de liberalidad digna de elogio y provechoso para quien la realizaba" (Pérez, 1997). En la época de Justiniano, específicamente en el Digesto hay un capítulo que hace referencia al arbitraje el cual menciona temas como el laudo y penalidades (Herazo, 2009, p. 3).

En España, el Fuero Viejo de Castilla comprendía un sistema de enjuiciamiento civil, refiriéndose al avenimiento de los litigantes obtenido por amigos comunes, o por los llamados "árbitros arbitradores". La Ley de las Siete Partidas, expedida durante el reinado de Alfonso X o el Sabio, consagraron la distinción entre los árbitros avenidores (fallo en derecho) y los amigables componedores (fallo en equidad) (Herazo, 2009, p. 17).

3 Las partes definía el objeto del litigio en un contrato procesal llamado fórmula y que caracterizó a la litis contestatio como la fase esencial del proceso (Fabrega, 1997). 
Más adelante, en la edad media, los gremios comerciales y de mercaderes de muchas ciudades de Europa, sintieron la necesidad de resolver sus conflictos sin la imposición de una autoridad externa, debido a la naturaleza especial de sus controversias, por lo que la figura de la mediación y hasta cierto punto la del arbitraje representaron una fórmula idónea para preservar su independencia (Carulla, 2001).

En la antigua China, la conciliación y la mediación fueron los principales métodos para resolver diferencias, esto a raíz de las enseñanzas de Confucio quien predicaba que la armonía natural no debía ser perturbada por procedimientos de confrontación, ya que estos eran la antítesis de la armonía misma. En la actualidad en China se estima que hay 950 mil comités populares de mediación con 6 millones de mediadores. Algunas técnicas de este mecanismo fueron introducidas en los Estados Unidos en la última mitad del siglo XIX, como consecuencia de migración del pueblo chino a este país (Barret, 2004).

Ya en la época moderna en los Estados Unidos ha sido el país donde más auge han tenido estos métodos alternativos; los primeros cuáqueros ejercían tanto la mediación como el arbitraje para resolver sus disputas comerciales. Más adelante, las asociaciones comerciales de determinados sectores industriales, cuyas empresas habían tenido que tratar entre sí, establecieron sus propios canales privados de resolución de diferencias.

Un paso importante en este ámbito se dio en 1768 cuando nació el arbitraje comercial a través de la Cámara de Comercio de Nueva York, la cual creó, y con bastante éxito, su propia vía de resolución de controversias, basada más en los usos comerciales que en los principios legales.

Sin embargo, los antecedentes y modelos de mediación más conocidos en los Estados Unidos provienen de los procedimientos de resolución de desavenencias laborales, de manera que ya en la década de los años treinta y principios de los cuarenta varios estados federales y algunas ciudades comenzaron a poner en marcha un programa de mediación para resolver los conflictos entre patrones y obreros, el cual trajo como consecuencia la creación, durante la Segunda Guerra Mundial, de la Junta Laboral de Guerra. 
Posteriormente, en 1947 se creó una oficina independiente para la resolución de conflictos laborales a la que se denominó Instituto Federal de Mediación y Conciliación (Singer, 1996, pp. 18-19).

Asimismo, se destaca en 1926 la fundación de la Asociación Americana de Arbitraje, organización de servicios públicos sin ánimo de lucro, que cuenta con amplia experiencia en la resolución de controversias a través de la mediación, el arbitraje y otras formas de solución extrajudiciales. ${ }^{4}$

Cabe distinguir en el movimiento ADR de los Estados Unidos tres etapas importantes (Barona, 1999, p. 53): la primera en la década de los años sesenta, que se caracterizó por buscar mecanismos de consenso, verdaderas alternativas centradas fundamentalmente en lo que serían litigios vecinales; la segunda fase, ya en la década de los años setenta, específicamente en 1976, Warren Burger, Magistrado del Tribunal Supremo, convocó una Conferencia Nacional sobre las causas de descontento popular con la Administración de Justicia, mejor conocida como la Conferencia Pound en conmemoración del 70. ${ }^{\circ}$ aniversario del discurso de Roscoe Pound de 1906 en la ABA 5 acerca de la reforma judicial. La conferencia Pound se considera como el momento en que nace en la época moderna el movimiento ADR. En esta conferencia, Burger habló acerca de los problemas del poder judicial, particularmente acerca de los problemas de retrasos y altos costos en la administración de justicia, sugiriendo una reforma en la que se diera

4 Es una organización de servicio público sin ánimo de lucro que cuenta con 38 sucursales en los Estados Unidos.

Función La Asociación Americana de Arbitraje (AAA) administra los procedimientos de arbitraje, mediación, etcétera. Alrededor de 8 mil litigios son administrados cada año a nivel nacional. A nivel internacional ella administra su Reglamento de Arbitraje Internacional. La Asociación ofrece asistencia para la concepción y puesta en práctica de alternativas de solución de conflictos a solicitud de las sociedades, de organismos gubernamentales, de oficinas de abogados y de tribunales con la intención de solucionar conflictos relacionados con el trabajo, el consumo, la tecnología, la salud pública, el comercio internacional, etcétera. Ofrece programas de formación para las personas implicadas en la solución de controversias, en tanto que terceros neutrales o consejeros de las partes. Mantiene una lista de alrededor 18 mil árbitros. Desarrolla reglas de ética para los árbitros y normas de conducta para los mediadores. Edita publicaciones como el Dispute Resolution Journal y el ADR Currents (Véase: http://www.adr.org/about).

5 Acrónimo en inglés para American Bar Association. 
un papel preponderante a los mecanismos alternativos de resolución de controversias (Stone, 2004).

La conferencia Pound sirvió para avivar el interés de las instituciones legales por las vías alternativas de resolución de conflictos, así como también para la proliferación de técnicas conciliatorias y la aparición de nuevos profesionales e instituciones dispuestas a usarlas.

Es importante destacar que en esta década se impulsa también el "Proyecto de Negociación de Harvard", surgido en 1978 como resultado de las investigaciones de un grupo de académicos, entre ellos, Roger Fisher. Este proyecto centró sus esfuerzos principalmente en la aplicación de métodos no adversariales en el plano empresarial, comunitario, político e internacional con gran repercusión en este ámbito.

La tercera etapa, a partir de los ochenta, supone la inclusión y expansión de estas modalidades a todas las áreas cualquiera que fuera la naturaleza de las posibles disputas existentes, producto de la necesidad de buscar soluciones más económicas que las que el sistema legal ofrecía.

En la década de los noventa hubo gran actividad legislativa en la materia, promulgándose una de las más importantes leyes aprobadas por el Congreso de los Estados Unidos, la Ley de Reforma de la Justicia Civil de 1990, que exigía a los juzgados de distritos federales que elaboraran e instaurasen sus propios planes para disminuir gastos en los procesos civiles para impulsar programas de resolución alternativa de litigios. Esto dio como resultado que los jueces ordenaran con mayor frecuencia el uso de la mediación resolviéndose un gran número de los asuntos a través de esta (Singer, 1996, p. 222).

En el ámbito privado, Martindale-Hubbell, en cooperación con AAA, ${ }^{6}$ publicó en el año 1995 la edición premier del Directorio de Resolución de Disputas. El libro está conformado por cuatro importantes secciones: empieza con 50 páginas que describen 13 procesos distintos de ADR; sigue con 36 páginas que analizan 10 áreas distintas de aplicación de estos mecanismos; el grueso ma-

6 Acrónimo en inglés para: American Arbitration Association 
yor del libro lo conforman 1949 páginas que enlistan las organizaciones e individuos que proveen este servicio de ADR en los 50 estados del territorio americano; la última parte contiene reglas, códigos, estándares éticos y un glosario. El directorio se halla disponible en la actualidad en internet. ${ }^{7}$

A nivel internacional, resulta significativa la labor de la fundación de la Cámara Internacional de Comercio en 1923, institución pionera en arbitraje a nivel internacional ${ }^{8}$ y las profundas implicaciones de la Convención de Nueva York sobre el reconocimiento y la ejecución de las sentencias arbitrales extranjeras de 1958 de la Naciones Unidas (CNUDMI, 1958), en el mercado internacional, al propiciar la consolidación de los arbitrajes a nivel transnacional.

En Europa, la creación del mercado único y la implantación de una moneda única aumentaron las transacciones económicas entre los estados miembros. Fue entonces cuando los ADR empezaron a representar una prioridad política para las instituciones de la Unión Europea. En 1986 el Comité de Ministros del Consejo de Europa -a través de su Recomendación 12/1986 (Consejo de Europa, 1986) señaló al arbitraje "como una alternativa más accesible y más eficiente que la acción judicial”. A partir de entonces han sido adoptadas algunas importantes iniciativas, entre las que se encuentran las Recomendaciones de la Comisión Europea el 30 de marzo de 1998 (Unión Europea, 1998) y de 4 de abril de 2001 relativas a los principios aplicables a los órganos extrajudiciales de resolución de litigios en materia de consumo (Unión Europea, 2001). Más recientemente, la Comunicación de la Comisión Europea sobre "estrategia en materia política de los consumidores 2002-2006 (Unión Europea, 2002)" destaca cómo la resolución alternativa de conflictos resulta medio idóneo para las controversias transfronterizas. Algo más adelante fue promulgada la importante Directiva comunitaria 2008/52/CE sobre ciertos aspectos de la mediación en asuntos civiles y mercantiles (Unión Europea, 24). Este paquete legislativo busca mejorar la protección a los consumidores en la Unión Europea en relación a los conflictos derivados de transacciones transnacionales.

7 Para más información véase: http://dispute.martindale.com/index.php

8 Para más información véase: http://www.iccwbo.org/ 
Refiriéndonos al caso mexicano, cabe destacar que aun cuando es un país que ha suscrito la Convención de Nueva York de 1958, sobre Reconocimiento y Ejecución de las Sentencias Arbitrales Extranjeras y también la Convención Interamericana sobre Arbitraje Comercial Internacional o Convención de Panamá de 1975, no fue sino a partir de la firma del Tratado de Libre Comercio con América del Norte cuando estos mecanismos comenzaron a adquirir relevancia. Así las cosas, en 1993 el Código de Comercio fue reformado para incorporar a sus artículos un capítulo sobre el Arbitraje Comercial, adoptando la Ley Modelo de La Comisión de las Naciones Unidas para el desarrollo del derecho Mercantil Internacional.

A partir de entonces ha habido muchos avances en la materia en México, el más importante, acaecido el 18 de junio de 2008 cuando se incorporan los ADR por primera vez como un derecho constitucional del gobernado al adicionar el tercer párrafo del artículo 17 de la Constitución Política de los Estados Unidos Mexicanos, el cual simplemente señala: "Las leyes preverán mecanismos alternativos de solución de controversias".

\section{BREVE HISTORIA Y SITUACIÓN ACTUAL DE LOS ADR EN SEDE JU- DICIAL EN EL ESTADO DE CHIHUAHUA}

Los mecanismos extrajudiciales de resolución de conflictos en sede judicial son relativamente nuevos en el estado de Chihuahua. Surgen de la necesidad de eliminar la sobrecarga de trabajo de los órganos jurisdiccionales y evitar a los particulares juicios largos y los altos costos que implican un litigio ante tribunales. Sin embargo, cabe apuntar que su implementación en un principio fue complicada y se podría decir que poco exitosa, en virtud de una clara ausencia de una actitud institucional abierta que permitiera la participación de la ciudadanía en la solución de sus propios conflictos. Sin embargo, tras un inicio difícil, actualmente se están posesionando paulatinamente como una opción eficaz para la resolución de conflictos. 


\section{Ley de mediación del estado de Chihuahua}

Los primeros esfuerzos de implementación de ADR en sede judicial se dieron el 7 de junio de 2003, cuando se publica en el Periódico Oficial Núm. 46 la Ley de mediación del estado de Chihuahua, cuyo objetivo primordial era regular la utilización de dicho mecanismo alterno para la solución de conflictos en materia civil, mercantil y familiar. La ley en comento contemplaba la creación del Centro Estatal de Mediación, como órgano desconcentrado del Poder Judicial, con la finalidad de organizar y promover la mediación. La idea era que existiera un Centro Estatal y varios Centros Regionales distribuidos en el Estado de Chihuahua con las siguientes atribuciones: i) estudiar y difundir técnicas de mediación, ii) instituir un registro de mediadores que formaran parte del Centro, así como mediadores independientes; iii) vigilar los procesos de mediación se llevaran a cabo en los términos de la ley, iv) formalizar convenios presentados por mediadores particulares y v) atender quejas y sugerencias en relación con los servicios prestados por dichas instituciones.

El ordenamiento en comento proponía un procedimiento de mediación completamente flexible y diseñado por las partes y el mediador, en virtud del cual, según el artículo 5 de la Ley de mediación, un tercero imparcial y capacitado, denominado mediador, sería el encargado de facilitar a los involucrados en una disputa la comunicación y la negociación a fin de lograr una solución parcial o total del conflicto. La mediación podía iniciarse antes del comienzo de un juicio o dentro de un proceso jurisdiccional, de oficio o a instancia de parte, en cualquier etapa del procedimiento. Cabe destacar que la Ley permitía la existencia tanto de mediadores adscritos al Centro, como mediadores independientes. Los convenios derivados un proceso de mediación tendrían los efectos de una transacción, siempre y cuando hubieran sido sancionados y aprobados conforme a la Ley. Ahora bien, desafortunadamente dichas disposiciones fueron ignoradas por varios gobiernos estatales por más de una década, lo que trajo como consecuencia que Chihuahua fuera de las pocas entidades federativas en el país sin un Centro de Justicia Alternativa adscrito al Poder Judicial. 
Por otro lado, resulta interesante destacar que el 9 de diciembre de 2006 se publica en el Periódico Oficial del Estado de Chihuahua la Ley de Justicia Penal Alternativa del Estado de Chihuahua, la cual crea un Centro de Justicia Alternativa, no adscrito al Poder Judicial sino dependiente de las Fiscalías de Investigación y Persecución del Delito, esto como parte acciones del entonces nuevo Sistema de Procuración de Justicia, convirtiendo a Chihuahua en la primera entidad federativa en México, que además de incorporar el juicio oral, cuenta con una institución de esta naturaleza, cuyo objetivo es ayudar a las partes, víctima u ofendido y el imputado, a través de diversos mecanismos extrajudiciales de resolución de conflictos, tales como la mediación, conciliación, juntas de facilitación, etcétera, para lograr, de forma voluntaria y colaborativa, la reparación del daño causado por un delito, lo que se conoce como justicia restaurativa (Márquez y De Villa, 2012, p. 114).

La ley en comento regula, en principio, un procedimiento pre procesal en donde se aplican medios alternos de solución de conflictos en materia penal, para ciertas conductas en los términos del Código Penal y Código de Procedimientos Penales del Estado de Chihuahua. El ordenamiento también señala, en su artículo 27 y 29, que los medios alternos se pueden utilizar en cualquier etapa del procedimiento penal, a instancia de los Jueces de Garantías y/o de los Agentes del Ministerio Público. Cabe mencionar que el Centro de Justicia Alternativa empezó a funcionar el $1 .{ }^{\circ}$ de enero de 2007 con mucho éxito. De acuerdo con el periódico Reforma, el segundo día de trabajo se habían resuelto 16 casos a través de esta instancia en la Ciudad de Chihuahua (Reforma, 2 de enero de 2007, p. 2).

Tomando como base lo anterior y tras la reforma de 2008 del tercer párrafo del artículo 17 Constitucional ${ }^{9}$ y, además el reconocimiento por parte del Poder Judicial Federal en el 2013 respecto a que "el acceso a los mecanismos alternativos de solución de controversias, como derecho humano, gozan de la misma dignidad que el acceso a la jurisdicción" (Tribunal Colegiado de Circuito, 2013, p. 1723), los ADR cobran un renovado protagonismo no solo a

9 Esta reforma del tercer párrafo del artículo 17 Constitucional señala: "Las leyes preverán mecanismos alternativos de resolución de controversias". 
nivel nacional, sino también en el estado, lo que trajo como resultado que, después de 11 años de la publicación de la Ley de Mediación, naciera en el estado de Chihuahua, el 23 de septiembre de 2014, el primer Centro de Mediación como un órgano auxiliar del Poder Judicial del Estado de Chihuahua, siendo este antesala del actual Instituto de Justicia Alternativa (IJA), para ello, el 29 de octubre de 2014, se publica en el Periódico Oficial al Estado, la nueva Ley Orgánica del Poder Judicial del Estado de Chihuahua, la cual en su artículo 176 crea el Instituto de Justicia Alternativa como un órgano desconcentrado del Poder Judicial, para la solución de controversias en materia civil, mercantil, familiar y penal a través de diversos mecanismo alternos, con competencia en todo el territorio del Estado.

Ante dicha reforma, la multicitada Ley de Mediación fue insuficiente para regular las atribuciones encomendadas a dicha Instancia Especializada del Tribunal Superior de Justicia del Estado de Chihuahua por varias razones, entre las que se destaca: primero, que el recién creado ijA se le otorgó competencia en materia penal, lo cual desde mi particular punto de vista era innecesario en virtud de que, como ya se apuntó, desde el 2007 están en funcionamiento los Centros de Justicia Alternativa adscritos a las Fiscalías de Investigación y Persecución del Delito para la resolución de conflictos en dicha materia, los cuales operan con bastante éxito; ${ }^{10}$ y segundo, el Instituto de Justicia Alternativa se le da facultad para promover diversos mecanismos extrajudiciales de resolución de conflictos, no únicamente la mediación, lo cual fue bastante acertado, pues puede resultar insuficiente para determinado tipo de conflictos y es necesario utilizar otros mecanismos más idóneos.

10 Cabe agregar que el 29 de diciembre de 2014 se publica en el Diario Oficial de la Federación la Ley de Nacional de Mecanismos Alternativos de Solución de Controversias en Materia Penal, el cual entró en vigor en los mismos términos y plazos que el Código Nacional de Procedimientos Penales, el cual también contempla la aplicación de ADR en esta área del derecho. 


\section{Ley de justicia alternativa del estado de Chihuahua}

Con base en lo anteriormente expuesto, el 30 de mayo de 2015 se publica en el Periódico Oficial, la Ley de justicia alternativa del estado de Chihuahua, la cual, sobra decir, abroga la Ley de Mediación. Este ordenamiento tiene varios objetivos, tales como: i) fomentar y difundir la cultura de paz mediante la restauración de relaciones interpersonales y sociales; ii) promover y regular las aplicaciones de ADR para la prevención y solución de conflictos; iii) regular la creación de Centros en sede judicial y privados; iv) fijar los requisitos y condiciones para el ejercicio profesional de los facilitadores. A continuación, se hará un breve análisis de los apartados más relevantes de la Ley.

a) Disposiciones generales

En el primer apartado de la ley en comento, se crea un glosario mucho más amplio del que se encontraba en la abrogada Ley de Mediación, que incluye conceptos nuevos, entre los que se destacan: "facilitador", para referirse al especialista capacitado y certificado para conducir los ADR en los términos de la ley. También se encuentra el de "justicia restaurativa", el cual, ante una falta de técnica legislativa, se define como un mecanismo alterno de solución de conflictos, lo cual es incorrecto, ya que el término apropiado es asamblea restaurativa o juntas restaurativas cuya finalidad es lograr una justicia restaurativa.

b) Mecanismos alternativos en lo particular

En esta parte de la Ley de Justicia Alternativa, se define mediación, conciliación y justicia restaurativa. Refiriéndome a las primeras dos, considero que estos conceptos se debieron incluir en el glosario, pues esa es su función, establecer significados y en relación a la tercera, justicia restaurativa, ya se había incluido en el glosario, se repite en este apartado y se incurre en el mismo error antes señalado. Por otro lado, la ley especifica que estos mecanismos alternos pueden ser utilizados tanto por instituciones públicas como privadas. Refiriéndose a estas últimas, establece que los facilitadores privados deberán estar certificados y capacitados, la pregunta que surge es ¿qué pasa con los facilitadores públicos?, ¿ellos no deben estar certificados y capacitados? 
Cabe destacar que en este capítulo se incluye un apartado con siete principios rectores de los ADR, entre los que se encuentran la justicia restaurativa, otra vez, lo cual crea confusión, ya que no queda claro si para efectos de esta ley, la justicia restaurativa es un principio que rige a los mecanismos alternos o es propiamente un mecanismo alterno de solución de conflictos, con la crítica que ya se ha hecho al respecto. Así mismo, el artículo 12 de la Ley en comento establece 5 principios relacionados con el desempeño de los facilitadores, los cuales algunos de ellos sus definiciones son bastante pobres y confusas, por ejemplo, el de honradez que al texto señala: "deberán comportarse con rectitud y expresarse con coherencia (énfasis añadido) y sinceridad, de acuerdo con la verdad y justicia".

c) Usuarios del servicio

De acuerdo con la Ley, los usuarios de estos servicios pueden ser personas físicas, de cualquier edad, y también incluye personas privadas de su libertad o bajo medida cautelar, así como personas morales. Cabe destacar que la ley establece una serie de derechos y obligaciones para los usuarios del servicio. Entre ellos llama la atención la obligación que se encuentra en el artículo 15, fracción IV, que al texto señala: "Asistir a todas las sesiones que sean programadas, salvo cuando exista causa justificada"; el cual se contrapone claramente con el principio de voluntariedad establecido en la Ley en comento.

d) Procedimiento

En la parte del procedimiento lo único que la Ley establece es el cuándo (énfasis añadido) se pueden utilizar estos mecanismos alternativos y lo hace de una forma bastante desordenada. En su artículo 30, fracción I se especifica que se tramitaran "al inicio de cualquier procedimiento", lo cual que no queda muy claro, tal vez la Ley se refiere a que se puede empezar un proceso ADR, antes del comienzo de un juicio, ya que en que en la fracción segunda habla de los casos en que el juicio ya se inició para materia civil y familiar. Luego señala en su fracción III respecto a la materia penal y de adolescentes, especificando que puede ser antes del inicio de un juicio y en la etapa de ejecución. 
En cuanto al cómo (énfasis añadido), la Ley únicamente habla de sesiones orales, conjuntas e individuales, y especifica que la solicitud para utilizar mecanismos alternos de solución de conflictos, hecha por un particular, el ordenamiento no lo aclara, debe ser calificada por el Instituto a fin de determinar si puede legalmente solucionarse a través de ADR. Todo lo demás, según el ordenamiento en comento se sustanciará de acuerdo con lo dispuesto en un reglamento, que a la fecha ${ }^{11}$ no se ha expedido.

e) Convenios y acuerdos

En este apartado se puede apreciar una novedad significativa, los convenios ratificados y sancionados por el instituto, tendrán el carácter de sentencia ejecutoriada, en otras palabras, el convenio produce el efecto jurídico de cosa juzgada, a diferencia de la abrogada Ley de Mediación, en la que el acuerdo solo tenía los efectos de una transacción. Además, la Ley establece la opción, en su artículo 37, de que, en caso de incumplimiento, las partes pueden acudir nuevamente al Instituto para elaborar un convenio modificatorio, hacer uno nuevo o bien, solicitar la ejecución en vía de apremio.

f) Servicio privado en materia de mecanismos alternativos Una de las posibilidades que establece la Ley de Justicia Alternativa, que también consideró la abrogada Ley de Mediación, es que el sector privado ofrezca estos servicios de resolución de conflictos a la ciudadanía a la par con el IJA. El ordenamiento habla de facilitadores privados, para distinguirlos de los que laboran en el Instituto de Justicia Alternativa, los cuales deberán ser certificados por dicha Institución, a través de una serie de requisitos que la propia Ley establece, entre los que se destacan: tener título y cédula de licenciado en Derecho y acreditar experiencia profesional mínima en materia penal, de adolescentes, civil o familiar. El artículo 45 de la Ley, autoriza a los facilitadores privados a crear centros de justicia alternativa, siempre y cuando cumplan con los siguientes requisitos: i) una solicitud dirigida al director del instituto, ii) contar con instalaciones físicas adecuadas para proporcionar el servicio, iii) tener al menos tres facilitadores pri-

11 Primavera de 2016. 
vados debidamente certificados por el Instituto y iv) contar con un proyecto de reglamento interno, el cual deberá ser validado y autorizado por el Instituto. La autorización para operar tiene una vigencia de dos años, y después se tendrá que hacer un trámite de renovación.

La Ley de justicia alternativa establece la obligación al instituto de vigilar, tanto a facilitadores, como centros privados, a través de visitas periódicas o quejas de los usuarios del servicio. También faculta al IJA a establecer sanciones en caso de probar alguna infracción por parte del sector privado. Las sanciones van desde amonestación escrita, hasta cancelación del registro. Cabe poner de manifiesto que el artículo 65 de la Ley de Justicia Alternativa, señala que tanto las resoluciones que establezcan infracciones, como las que niegue las solicitudes de autorización, acreditación, renovación o certificación, pueden ser impugnadas ante la Sala de lo Contencioso Administrativo y Fiscal, para todas las demás resoluciones del Instituto, se establece un recurso de revocación, del cual conocerá el director del ijA, haciéndolo juez y parte.

Ahora bien, a pesar de las deficiencias que presenta la Ley, el Instituto de Justicia Alternativa del Estado de Chihuahua desde su inicio, en el año 2014, ha operado con buenos resultados. El trabajo y dedicación de las personas que conforman el instituto es admirable, su compromiso con el proyecto de ayudar a los particulares a resolver sus propios conflictos a través de la mediación y conciliación es evidente. Cabe destacar que, en el primer semestre del año 2015, solo en el Distrito Judicial Morelos, se habían atendido 1809 casos, de los cuales 406 llegaron a un convenio (Instituto de Justicia Alternativa, 2015). Si bien es cierto, la cantidad de convenios representa el $22 \%$ de los expedientes, también lo es que, para ser un proyecto relativamente nuevo, los datos son bastantes alentadores.

Considero que el Instituto de Justicia Alternativa del Estado de Chihuahua está cumpliendo con misión y visión de contribuir al fortalecimiento de las relaciones personales de la sociedad al proporcionar un servicio gratuito, de calidad, flexible, respetuoso y, sobre todo, profesional. Además, se esfuerza por alcanzar sus objetivos de promover una cultura de la paz a través de la 
implementación de programas en coordinación con otras instituciones, en el caso de Ciudad Juárez, ha realizado convenios de colaboración con la Universidad Autónoma de Ciudad Juárez y con la Secretaría de Desarrollo Social en el municipio, por mencionar algunos (Instituto de Justicia Alternativa del Estado de Chihuahua, 2015).

\section{PERSPECTIVAS HACIA EL FUTURO}

A pesar de los importantes avances que se han dado, no solo en el estado de Chihuahua, sino también en el país, los mecanismos alternativos de resolución de conflictos todavía tienen un largo camino por recorrer. Romper paradigmas no es una tarea fácil, pero definitivamente se han dado los primeros pasos para que así sea, uno de ellos y quizá de los más importantes es que los usuarios de estos servicios han podido vivir los beneficios que estos sistemas alternos ofrecen tales como:

- Rapidez en la resolución de conflictos

- Servicio profesional sin costo

- Procedimiento adaptado a las necesidades de las partes

- Cumplimiento de los acuerdos de forma voluntaria

- Satisfacción respecto del resultado del proceso por ambas partes del conflicto

- Prevención de conflictos futuros, pues las partes aprenden a comunicarse.

Ahora bien, surge la pregunta, ¿cuáles son las perspectivas de estos mecanismos alternos de resolución de conflictos en el Estado de Chihuahua y en el país? Sería muy pretencioso de mi parte tratar de predecir el futuro, nadie puede hacerlo, pues son muchos los factores en juego, lo que sí tengo claro es que los ADR deberían permanecer y considerarse como una opción viable para la solución eficaz de cierto tipo de conflictos, en virtud de que rompen con las formalidades y rigidez que caracterizan al procedimiento ante tribunales, con todo lo que esto implica. Cabe aclarar que con esto no quiero decir que los ADR deberían sustituir al sistema 
tradicional de justicia, definitivamente no es su objetivo, todo lo contrario, su finalidad es complementarlo y junto a él, mejorar el acceso a la justicia de los ciudadanos, no solo en el estado de Chihuahua, sino en todo el país.

Así, todavía tienen algunos obstáculos por vencer, uno de los más importantes es el escepticismo por parte de abogados y juristas en relación a la eficacia de estos mecanismos alternos en la solución de conflictos. Considero que resulta indispensable un cambio radical en la mentalidad de los abogados a fin de que sean ellos los que inviten a las partes a elegir esta opción para solucionar sus conflictos antes de acudir a los tribunales, en lugar de desalentarlos como actualmente todavía lo hacen muchos de ellos, argumentando que son una fórmula que no corresponde a nuestra tradición jurídica, lo cual es totalmente falso, ya que en México se han utilizado desde hace algunas décadas en materia laboral y del consumidor con bastante éxito.

Ahora bien, lo cierto es que la simple regulación de los mecanismos alternativos de resolución de conflictos en sede judicial no es garantía de éxito, resulta indispensable, además, un esfuerzo conjunto por parte de los diferentes actores involucrados a fin de evitar que se conviertan en uno de los tantos proyectos ineficaces que el gobierno ha puesto en marcha para mejorar la impartición de justicia. Es importante tomar en cuenta la experiencia de otros países $^{12}$ y de algunas entidades federativas en México que han implementado ADR en sede judicial, la cual ha puesto de manifiesto que los beneficios de disminuir la carga de trabajo de los tribunales, el cual es uno de sus objetivos primordiales de los ADR en sede Judicial, ${ }^{13}$ no se percibe a corto plazo, por el contrario, es un proceso largo y en principio bastante costoso por toda la infraestructura y capital humano que se necesita para brindar este servicio en todo el Estado. Sin embargo, considero que a pesar de los retos que los ADR han tenido que enfrentar y que siguen enfrentando, las posibilidades de éxito son bastante altas y tienen grandes posibilida-

12 Específicamente Estados Unidos, donde estos mecanismos alternos de solución de conflictos tienen una gran trayectoria y se encuentran consolidados.

13 Según lo específica la exposición de motivos de la Ley de Justicia Alternativa para el Estado de Chihuahua. 
des no solo que ayudar a solucionar conflictos entre particulares, sino de establecer una verdadera cultura de paz.

\section{BIBLIOGRAFÍA}

Carulla, P. (2001). Mediación: una alternativa eficaz para resolver conflictos empresariales. Anuario de Justicia Alternativa, 1.

CNUDMI (1958). Convención sobre el reconocimiento y la ejecución de las sentencias arbitrales extranjeras. Nueva York: Naciones Unidas.

Consejo de Europa (1986). Recomendación 12/1986 referente a ciertas medidas tendientes a prevenir la sobre carga de trabajo de los Tribunales. Unión Europea.

Acceso a los mecanismos alternativos de solución de controversias, como derecho humano. Goza de la misma dignidad que el acceso a la jurisdicción del Estado, III.2o.C.6K (10a) (Tribunales Colegiados de Circuito, octubre 2013).

Barona, S. (1999). Solución extrajudicial de conflictos y Derecho Procesal. Valencia, España: Tirant Lo Blanch.

Barret, J. (2004). A history of Alternative Dispute Resolution: Story of a Political, Cultural and Social Movement. Estados Unidos: Jossey-Bass.

Fabrega, J. (1997). Medios alternativos de solución de conflictos con especial referencia a la República de Panamá y a la de Estados Unidos. XV Congreso Mexicano de Derecho Procesal. Santiago de Querétaro: UNAM.

Herazo, M. (2009). Costos de transacción en los mecanismos alternos de solución de conflictos en Colombia. Una interpretación desde la Escuela Neoinstitucional y el Teorema de Coase. Tesis de maestría inédita. Colombia: Universidad Externado.

Instituto de Justicia Alternativa del Estado de Chihuahua (2015, mayo 22). Objetivos. Chihuahua, Chihuahua, México.

Instituto de Justicia Alternativa (2015). Resumen de Estadística IJA a junio 2015. Estadístico, Tribunal Superior de Justicia, Instituto de Justicia Alternativa, Chihuahua.

Márquez, M. G., \& De Villa, J. C. (2012, mayo). La justicia restaurativa y la mediación penal en México. De Iure 11(8). 
Mancur, A. (2002). Ejercicio de la Jurisdicción del Estado a través de la Conciliación. Tesis inédita. Guatemala: Universidad Francisco Marroquín. Facultad de Derecho.

Pérez, C. (1997). La conveniencia presente y futura de utilizar medios alternativos en la solución de litigios. XV Congreso Mexicano de Derecho Procesal (p. 791). Santiago de Querétaro: UNAM.

Reforma. (2007, enero 2). Aplica Chihuahua Justicia Alternativa (H. Nájera, Ed.) Periodico Reforma.

Singer, L. (1996). Resolución de Conflictos. Técnicas de actuación en los ámbitos empresarial, familiar y legal. Buenos Aires: Paídos.

Stone, K. (2004). Alternative Dispute Resolutión. Encyclopedia of Legal History . Unión Europea. (2002, enero 15). Comunicación de la Comisión Europea sobre estrategias en materia política de los consumidores 2002-2006. DO L 11.

Unión Europea. (2008, mayo 24). Directiva 2008/52/CE del Parlamento Europeo y del Consejo relativa a determinados aspectos de la mediación en materia civil y mercantil. DO L 136/3 .

Unión Europea. (2001, abril 19). Recomendación 2001/310/CE, relativa a los principios aplicables a los órganos extrajudiciales de resolución de litigios en materia de consumo. DO L 109 .

Unión Europea. (1998, abril 17). Recomendación 98/257/CE, relativa a los principios aplicables a los órganos responsables de la solución extrajudicial de los litigios en materia de consumo. DO L 155. 